\title{
Heuristic algorithm based on Ant Colony Optimization for the Capacitated Location-Routing problem with Homogeneous Fleet
}

\section{Algoritmo heurístico basado en optimización para el problema de localización y ruteo con flota homogenea}

\author{
GATICA, Gustavo ${ }^{1}$ \\ ESCOBAR, John W. ${ }^{2}$ \\ LINFATI, Rodrigo ${ }^{3}$
}

\begin{abstract}
This paper considers the Capacitated Location-Routing Problem with Homogeneous Fleet (CLRP). The objective is to minimize the sum of the open depots' costs, the costs for the used vehicles, and the costs associated with the distances traveled. A metaheuristic algorithm of two phases for the CLRP is proposed. In the first phase, customers establish the clusters to be subsequently heuristically assigned to the depots. In the second phase, the initial routes are improved using an algorithm based on Ant Colony. The obtained results show the efficiency of the proposed approach.

Key words: capacitated location routing, ant colony, metaheuristic.

\section{Resumen}

Este artículo considera el problema de localización y ruteo capacitado con flota homogénea (CLRP). El objetivo es minimizar la suma de los costos de los depósitos abiertos, los costos de los vehículos usados y los costos asociados con las distancias recorridas. Se propone un algoritmo metaheurístico de dos fases para el CLRP. En la primera fase, los clústeres son establecidos por los clientes para luego ser asignados heurísticamente a los depósitos. En la segunda fase, se mejoran las rutas iniciales mediante un algoritmo basado en Colonia de Hormigas. Los resultados obtenidos muestran la eficiencia del algoritmo propuesto.

Palabras clave: localizacion y ruteo capacitado, colonia de hormigas, metaheurística
\end{abstract}

\section{Introduction}

The logistic function, "oriented to the customer," requires that the supply departments fulfill diverse requirements. In this way, it is necessary to apply specialized techniques to support customer service (i Cos \& De Navascués, 1998). The logistics include integrating different activities to reduce resources and costs through

\footnotetext{
${ }^{1}$ Full Professor. Faculty of Engineering. Universidad Andres Bello. Chile. Contact e-mail. ggatica@unab.cl

${ }^{2}$ Full Professor. Department of Accouting and Finance. Universidad del Valle. Colombia. Contact e-mail. john.wilmer.escobar@correounivalle.edu.co

${ }^{3}$ Full Professor. Department of Industrial Engineering. Universidad del del Bío-Bío. Chile. Contact e-mail. rlinfati@ubiobio.cl
} 
available solutions (García, 2016). The problem of location routing (LRP) is critical in logistics because it establishes criteria regarding the opening of depots and customers' assignment for a later routing. The problem presents externalities considering social, environmental, and financial activities and economic impacts within the transport of goods in the urban area. The problems from the depots' location, however, the location of the depots and an efficient routing is relevant and necessary to optimize for a better supply chain (Luna López, 2015; Vasquez Delgado, 2012, Escobar \& Linfati, 2012; Farkavcova et al., 2018).

The problem of location routing is NP-Hard (Garey \& Johnson, 1979) because when determining the opening of facilities, it simultaneously contributes to the problem of installation location (FLP) and subsequent vehicle routing (VRP) (Tokgoz \& Trafalis, 2014). Furthermore, for the solution of this problem, different approaches have been suggested through various algorithms; for example, exact methods: Baldacci et al. (2011), which solves the problem using strategies based on the well-known "Set Partition Problem"; Belenguer et al. (2011), and Contardo et al. (2010) with an exact approach based on the Branch-and-Cut algorithm. Harks et al. (2013) combined algorithms and lower limits for different relaxations allow applying cross-docking. Laporte et al. (1989) suggest a linear programming model optimally solved for small instances (less than 50 customers).

Duhamel et al. (2010) proposed heuristic methods based on greedy search (GRASP) for solving the LRP. Wu et al. (2002) suggested a method based on the decomposition of the problem into two subproblems: location and routing problems. Finally, metaheuristic algorithms have been proposed by Caballero et al. (2007), which show a real application of the problem in Andalucia, Spain. Algorithms based on Tabu search have been proposed by Linfati et al. (2014), which use an approach called granular tabu search to solve the location-routing problem heterogeneous fleet. Prins et al. (2006a) applied a GRASP based on an extended and random version of the Clarke \& Wright (1964) algorithm for the first and tabu search heuristic in the second phase. In this way, the article contributes to the state of the art of the LRP by employing a metaheuristic based on Ant Colony Optimization (ACO), with a performance equivalent to GRASP, MA|PM, and hybrid metaheuristics using the problem's benchmarks.

The literature review of the LRP considers characteristics of the distribution and logistics areas being applied in diverse applications such as garbage collection, vendor routing, location of train lines and subways, passenger transport, merchandise distribution, mail collection, and distribution, among others (Toro et al., 2017). However, few papers have been published dealing with the location routing problem efficiently satisfying the whole customer network and minimizing the total logistic cost (Toth \& Vigo, 2002).

The solutions regarding the location and routing vehicle problem have been studied since the last decade, generally solved by exact and heuristic algorithms. The VRP concept was introduced by Dantzig \& Ramser (1959). It was initially called the "Trucking Dispatching Problem," which is similar to the following VRP. Later, Clarke \& Wright (1964) formalized the classical Vehicle Routing Problem (Classic VRP). Thereby, over the years, several researchers consider different variants for the problem of VPR. First, the researchers analyzed the cost of routing for a facility's location (Webb, 1968). In this work, a cost function for each potential facility might not accurately represent the facility location problem. Second, Beardwood et al. (1959) suggested an approximate solution to the length of the route if the customers are uniformly distributed in a square. Finally, Watson-Gandy \& Dohrn (1973) use a heuristic procedure to solve a location routing by considering multi-depots such as Tuzun \& Burke (1999). 


\section{Methodology}

\subsection{Problem Formulation}

The Capacitated Location Routing Problem (CLRP) could be described by a complete graph problem as follows Escobar et al. (2015): Let be $G=(V, E)$ a complete graph non-directed, where $V=\{1, \ldots, m+n\}$ is the set of nodes and $E$ is the set of arcs that connects each pair of nodes $V$. The set of vertices is divided into two subsets, vertices $I=1, \ldots, m$ that corresponds to the potential depots and the other subset $J=m+1, \ldots, m+n$ with customers. There is a cost of trip $c_{i j}$ non-negative associated with each arc $(i, j) \in E$. Each depot $i \in I$ have a capacity $W_{i}$ and a fixed cost of opening $O_{i}$. Each customer $j \in J$ has a $d_{j}$ demand that the homogenous fleet of vehicles $K$ must fulfill, each with $Q$ capacity, that are available in each depot $i \in V$. Each vehicle, when used by one depot, performs a route that generates a fixed cost $F_{i}$. The CLRP considers the following constraints: i) each route must begin and end in the same depot; ii) the total cargo must not exceed the capacity of the vehicle $Q$; iii) each customer must be visited exactly once by a single route; iv) the total load of the assigned routes to one depot must be adjusted to the capacity of the depot $W_{i}$; and finally, v) the flow between depots are not allowed. The problem's objective is to determine which depots must be opened and which routes must be performed to minimize the total cost.

According to Prins et al. (2007), the formulation of the mathematical model of three index uses the following binary variables: $y_{\mathrm{i}}=1$ if the $i$ depot is open, $f_{\mathrm{ij}}=1$ if the customer $j$ is assigned to the depot $i$, and finally $x_{\mathrm{ijk}}=1$ if the $(i, j)$ arc is visited from $i$ to $j$ in the performed route by the vehicle $k \in K$. Then, the problem could be formulated as follows:

$$
\min z=\sum_{i \in I} o_{i} y_{i}+\sum_{i \in V} \sum_{j \in V} \sum_{k \in K} c_{i j} x_{i j k}+\sum_{k \in K} \sum_{i \in I} \sum_{j \in I} F_{i} x_{i j k}
$$

Subject to:

$$
\begin{array}{cl}
\sum_{u \in K} \sum_{i \in V} x_{i j k}=1 & \forall j \in J \\
\sum_{i \in I} \sum_{i \in V} d_{j} x_{i j k} \leq Q & \forall k \in K \\
\sum_{j \in V} x_{i j k}-\sum_{j \in V} x_{j i k}=0 & \forall i \in V, \forall k \in K \\
\sum_{i \in I} \sum_{j \in J} x_{i j k}=1 \quad & \forall k \in K \\
\sum_{i \in S} \sum_{j \in S} x_{i j k} \leq|S|-1 \quad \forall S \subseteq J, \forall k \in K \\
\sum_{u \in J} x_{i u k k}+\sum_{u \in V \backslash\langle i\}} x_{u j k} \leq 1+f_{i j} \quad \forall i \in I, \forall j \in J, \forall k \in K \\
\sum_{j \in J} d_{j} f_{i j} \leq W_{i} y_{i} \quad \forall i \in I \\
x_{i j k} \in\{0,1\} \quad \forall i \in V, \forall j \in V, \forall k \in K \\
y_{i} \in\{0,1\} \quad \forall i \in I \\
f_{i j} \in\{0,1\} \quad \forall i \in I, \forall j \in V
\end{array}
$$

The objective function (1) considers the sum of the open depots' costs, the trip costs associated with the visited arcs by the routes, and the fixed costs associated with the used vehicles. Constraints (2) guarantee that each customer belongs exactly to a route and only has one predecessor in its route sequence. Constraints (3) and (8) are associated with the depot's capacities and the customer. Constraints (4) and (5) ensure each route's continuity and determine that each route begins and ends in the same depot. Constraints (6) consider the 
elimination of sub tour. Constraints (7) specify that a customer must be assigned to a depot only if there is a route that joins them. Finally, constraints (9), (10), and (11) represent the integrality of the variables.

A solution of the CLRP must indicate the depots to be opened, the costumers to be assigned to each open depot (each customer must be assigned to only one depot), and the sequence of customers to satisfy their demand. The proposed algorithm uses two phases. The initial phase allows the opening of the best depots and considering some initial routes. Such routes are improved in the final phase by applying a metaheuristic algorithm based on Ant Colony. The suggested phases are described as follows.

\subsection{Initial Heuristic Procedure}

The initial procedure is implemented according to Escobar \& Linfati (2012) work, where the algorithm can obtain high-quality solutions with reduced computational times. This procedure combines exact and heuristic methods. The following steps are performed to generate the initial solution:

Step 1: Construct a TSP tour with all the customers using the library Lin-Kernighan (LKH) (Helsgaun, 2000) available in Stützle \& Ruiz (2018).

Step 2: The giant TSP tour is split into many customer groups, called clusters. The criterion to obtain the customer group is the vehicle capacity. Therefore, the first customer is determined to be assigned to a cluster corresponding to a vehicle $\mathrm{k} \in \mathrm{K}$. Then, one by one of the new customers are added following the TSP trip. Once the $\mathrm{k} \in \mathrm{K}$ vehicle's capacity is completed, the process restarts until all the customers are assigned to one cluster. This process selects the best customer assignment changing the initial customer iteratively to select the clusters.

Step 3: For each depot $\mathrm{i}$ and each cluster $\mathrm{g} \in \mathrm{G}$, the LKH procedure is applied to find the corresponding TSP tour. In this way, the route length $\left(l_{\text {ig }}\right)$ is obtained when depot $i$ is assigned to cluster $g$.

Step 4: The depots are assigned to the clusters solving the corresponding Single Source Capacitated Plant Location Problem (FLPS). The depots to be opened and the TSP tours assigned to each depot are determined. The FLPS model is the following (Barceló \& Casanovas, 1984):

$$
\min u=\sum_{i \in I} o_{i} y_{i}+\sum_{i \in I} \sum_{g \in G} l_{i g} x_{i g}
$$

Subject to:

$$
\begin{gathered}
\sum_{i \in I} X_{i g}=1 \quad \forall g \in G \\
\sum_{g \in G} d c_{g} X_{i g} \leq W_{i} y_{i} \quad \forall i \in I \\
x_{i g} \in\{0,1\} \quad \forall i \in I, \forall g \in G \\
y_{i} \in\{0,1\} \quad \forall i \in I
\end{gathered}
$$

The objective function (12) corresponds to the sum of the total costs of depots' opening and the costs associated with covered distance when the depots are assigned to the clusters. The constraints (13) guarantee that each customer group being strictly assigned to only one depot. Constraints (14) determine the capacity of each one of the depots. Finally, constraints (15) and (16) determine the binary variables group used in the model. Note that the initial procedure is repeated $n$ times, considering each customer as a start to split the TSP tour. In this procedure, the best feasible solution (best objective function) is kept (Linfati et al., 2014). 


\subsection{Improvement Phase Based on Ant Colony}

Biologically, ants explore randomly in their environment, from their nest to the hunt for food. Each time the ants explore, they depot a constant amount of pheromones, a chemical that other ants could smell and follow. Since ants are blind, this trace helps them move from one point to another under efficient routes, finding the shorter trips between the nest and the food (Negrotto, 2015). The main reason for their success in the battle for survival is that the ants cooperate (Dorigo \& Gambardella, 1997). The research of the ants' collective performance covers the analysis of their behavior when they transport and forage for food. The Ant Colony is an optimization algorithm based on swarm intelligence, imitate the behavior of an ant colony that hunts for food. The Algorithm was suggested by Dorigo (1992). In this investigation, each movement from one node to another considers the probabilistic artificial transition rule, defined by the probability that the ant $k$, located in the customer $r$, decides to move towards the customer $u$ (Dorigo, 1992).

$$
\rho=\frac{[\tau(\mathrm{r}, \mathrm{u})]^{\alpha} *[\eta(\mathrm{r}, \mathrm{u})]^{\beta}}{\sum_{k}[\tau(\mathrm{r}, \mathrm{u})]^{\alpha} *[\eta(\mathrm{r}, \mathrm{u})]^{\beta}}
$$

Where:

- $\tau(r, u)$ : is the pheromone from arc $r$ to $u$.

- $\eta(r, u)$ : is the heuristic information from the arc $r$ to $u$, also pointed out as 1.0 divided the distance between the customers.

- $\alpha$ and $\beta$ are weights that set the relative importance between pheromone levels and the local search criterion.

Once all the ants have constructed a complete trail from the initial node to the destination node, all the internal bonds (in case of existing) are eliminated, and every ant follows the constructed trail again to the initial node in a deterministic way (Colorni et al., 1992). In this process, it is deposited a specific amount of pheromone $\Delta \tau_{i j}^{k}$ in each connection.

$$
\Delta \tau_{i j}^{k}(t)=\frac{Q}{L^{K}(t)}
$$

Being $Q$, a constant $L^{k}(t)$ is the total length of the traveled arcs by the ant $\boldsymbol{k}$. The total value of pheromones for a single and after a tour (Colorni et al., 1992). In this way, the intensity of the trails is updated with the following formula:

$$
\tau_{i j}^{k}(t)=\tau_{i j}^{k}(t)+\Delta \tau_{i j}^{k}(t)
$$

Thus, the pheromone levels are updated in the arcs of TSP. Finally, it is considered the evaporation of pheromone as a way to discard poor trails (Colorni et al., 1992). The evaporation is modeled by the equation:

$$
\tau_{i j}^{k}(t)=\tau_{i j}^{k}(t) *(1-\rho)
$$

It is important to consider that $0<\rho<1$. The iterative process among each Hamiltonian cycle found by the ant process is depicted in Figure 1.

\section{Algorithm 1}

Pseudocode algorithm ant colony for TSP 
1: Input: NNodes, Parameters ACO $(\alpha, \beta, \rho, Q$, Maxiterations).

2: Output: TspTour.

3: Begin

4: $\quad$ Current Iteration $=0$

5: $\quad$ While Current Iteration < NNodes * Maxlterations do

6: $\quad$ While does not exist solution do

7: $\quad$ Select the next node for each ant.

8: $\quad$ End While

9: $\quad$ Random Diversification ()

10: $\quad$ Update Pheromone by considering parameters $\alpha$ and $\beta$ ()

11: $\quad$ Current Iteration ++;

12: $\quad$ End While

13: $\quad$ TspTour $=$ Tour of lower cost found by the ants.

14: End

We have considered three additional parameters to proposed approach ACO:

- NNodes: Amount of nodes that belong to TSP tour.

- MaxIterations: Parameters to determine the number of ACO iterations.

- TspTour: Solution of TSP tour indicating the order of visit to the node.

\subsection{Solution Improvement}

Initially, to improve each route, a TSP-ACO is applied. Then, local search procedures are applied, such as insertion and swap:

1. Insertion: A customer is removed from its current position, and it is inserted in another position in the same route or another route.

2. Swap: Exchange of two customers belonging to the same route or different routes.

The integration of the Ant Colony Optimization meta-heuristic and the Insertion and Swap local search are depicted in the Figure 2.

\section{Algorithm 2}

Pseudocode algorithm improvement phase

1: Begin

2: $\quad$ it $=0$

3: $\quad$ While it $<$ NumlT do

4: $\quad$ For each $i$ in the solution

5: ACO-TSP(route i)

6: $\quad$ End for

7: $\quad$ Local search - Insertion

8: $\quad$ Local search - Swap

9: it ++

10: $\quad$ End While

11: End

\section{Results}

\subsection{Calibration of Parameters}

The ACO algorithm uses four parameters: $\alpha, \beta, \rho, Q$. If $\alpha=0$, the closest costumers are the ones with more probability to be chosen (the classic algorithm of the gradient with different departure points). Thus, it is chosen 
the value of $\alpha=1$, following the algorithms' obtained information for similar problems that can be found in the literature (Colorni et al., 1992). If $\beta=0$, only the pheromone levels are taken into account, which implies very poor results, especially if $\alpha>1$ is a stagnation, where all the ants follow the same path converging to suboptimal solutions (Dorigo et al., 1996). Therefore, the literature's extremes ( 2 and 5 ) are chosen, besides $\beta=$ 8 , to identify what happens when this value is chosen; $\beta$ might be an arbitrary value. For $\rho$, the set values are between 0 and 1 , and this is the parameter that considers the biggest changes within the bibliographic review of TSP-ACO (Asmar et al., 2005; Dorigo \& Stützle, 2019; Mehrjerdi \& Nadizadeh, 2013). In consequence the values $\rho=\{0.2,0.5,0.8\}$ are chosen.

Table 1

Parameters ACO

\begin{tabular}{|c|c|c|c|c|c|}
\hline ACO algorithm & $\alpha$ & $\beta$ & $\mathrm{P}$ & $\mathrm{m}$ & $\tau 0$ \\
\hline AS & 1 & 2 to 5 & 0.5 & $\mathrm{n}$ & $\mathrm{m} / \mathrm{C}^{\mathrm{nn}}$ \\
\hline EAS & 1 & 2 to 5 & 0.5 & $\mathrm{n}$ & $(e+m) / \rho C^{n}$ \\
\hline ASrank & 1 & 2 to 5 & 0.1 & $\mathrm{n}$ & $0.5 r(r-1) / \rho C^{n}$ \\
\hline MMAS & 1 & 2 to 5 & 0.02 & $\mathrm{n}$ & $1 / \rho C^{n}$ \\
\hline ACS & - & 2 to 5 & 0.1 & $\mathrm{n}$ & $1 / n C^{n}$ \\
\hline
\end{tabular}

Source: Dorigo 1992; Dorigo et al., 1996

For Maxiterations, 5 and 30 are considered, and for NumIT 10 and 50. These parameters directly influence the solution's computational time; therefore, the upper ends were chosen according to the criterion of responding within short computing times. On the other hand, the lower ends were chosen according to the criterion of responding within a low computational time without affecting the solution's quality. In this way, it is proved only with both ends for the parameters combination.

Table 2

Calibration of Parameters

\begin{tabular}{|c|c|c|c|}
\hline \multicolumn{4}{|c|}{ Values } \\
\hline$\alpha$ & \multicolumn{3}{|c|}{1} \\
\hline $\mathrm{B}$ & 2 & 5 & 8 \\
\hline$\rho$ & 0,2 & 0,5 & 0,8 \\
\hline $\mathrm{Q}$ & \multicolumn{3}{|c}{1000000} \\
\hline Maxiteraciones & 5 & 30 \\
\hline NumIT & 10 & 50 \\
\hline
\end{tabular}

\subsection{Obtained Results}

Regarding the computational experiment, the best results are generated with the combination of parameters $\beta=2$ and $\rho=\{0.2,0.5\}$. Therefore, the analysis concludes that these values are appropriate to perform the test of the proposed algorithm. Furthermore, it is verified and discard the value of $\beta>5$ pointed out in the literature of Coloni et al., 1992).

The obtained results of the run tests for each of the following instances of the test are presented (Barreto, 2004; Tuzun \& Burke, 1999): 
Table 3

Instances of Test

\begin{tabular}{|c|c|c|c|}
\hline Source & Instances & Depots & Customers \\
\hline \multirow{6}{*}{ Barreto (2004) } & Christofides69-50x5 & 5 & 50 \\
\hline & Christofides69-75×10 & 10 & 75 \\
\hline & Christofides69-100x10 & 10 & 100 \\
\hline & Daskin95-88x8 & 8 & 88 \\
\hline & Daskin95-150x10 & 10 & 150 \\
\hline & Min92-134x8 & 8 & 134 \\
\hline \multirow{4}{*}{ Tuzun \& Burke (1999) } & 111112 & 10 & 100 \\
\hline & 111122 & 20 & 100 \\
\hline & 132222 & 20 & 150 \\
\hline & 123222 & 20 & 200 \\
\hline
\end{tabular}

Source: Owner

The proposed algorithm (HACO) has been compared with the following heuristics published for the CLRP: GRASP (Prins et al., 2006b), MA|PM (Prins et al., 2006a), LRGTS (Prins et al., 2007), GRASP+ELS (Duhamel et al., 2010), SALRP (Vincent et al., 2010), 2-Phase HGTS (Escobar et al., 2013) and GSA (Escobar \& Linfati, 2012). The reported results for GRASP, MA|PM, LRGTS, SALRP, and 2-Phase HGTS correspond to only one run of the associated algorithm. Finally, GRASP + ELS executed five times with five random seeds, reports the best result of the runs with their computational time. Table 4 and 5 shows the results.

Table 4

Comparison Instances Barreto (2004)

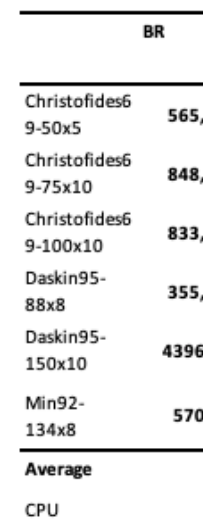

\begin{tabular}{|c|c|c|}
\hline \multicolumn{3}{|c|}{ GRASP } \\
\hline Cost & Gap BR & CPU time \\
\hline 599,1 & 5,92 & 3 \\
\hline 861,6 & 1,5 & 10 \\
\hline 861,6 & 3,38 & 26 \\
\hline 356,9 & 0,31 & 18 \\
\hline 44625 & 1,5 & 156 \\
\hline \multirow[t]{4}{*}{5965,1} & 4,49 & 50 \\
\hline & 2,85 & 44 \\
\hline & & Pentium 4 \\
\hline & & $(2.4 \mathrm{GHz})$ \\
\hline
\end{tabular}

\begin{tabular}{rrr}
\hline \multicolumn{3}{c}{ MA|PM } \\
Cost & Gap BR & CPU time \\
\hline 565,6 & 0 & 4 \\
866,1 & 2,03 & 9 \\
850,1 & 2 & 45 \\
355,8 & 0 & 34 \\
44012 & 0,11 & 255 \\
5950 & 4,22 & 111 \\
\hline & 1,39 & 76 \\
& & Pentium 4 \\
& & $(2.4 \mathrm{GHz})$
\end{tabular}

\begin{tabular}{crr}
\hline \multicolumn{3}{c}{ LRGTS } \\
Cost & Gap BR & CPU time \\
\hline 586,4 & 3,68 & 3
\end{tabular}
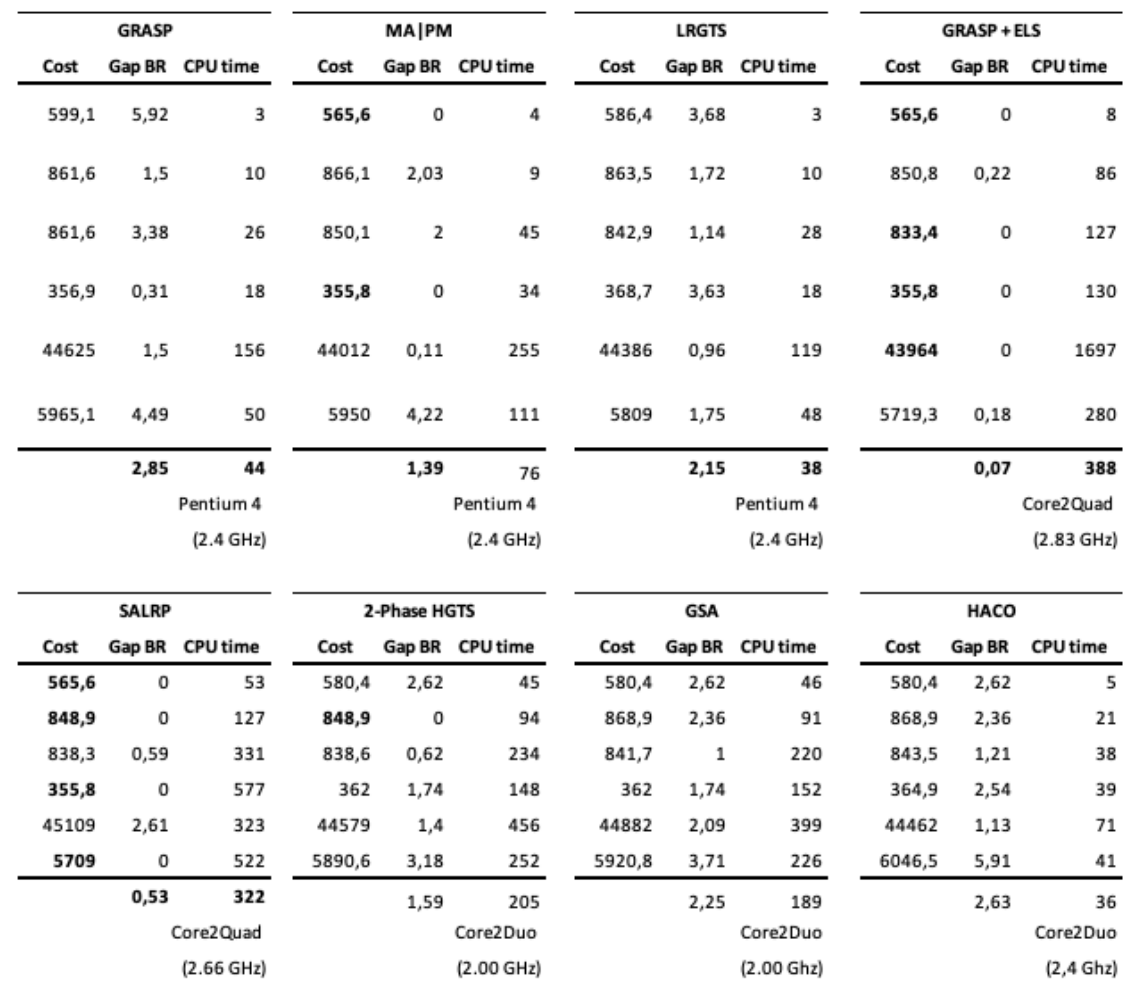

$355,8 \quad 0 \quad 130$

$43964 \quad 0 \quad 1697$
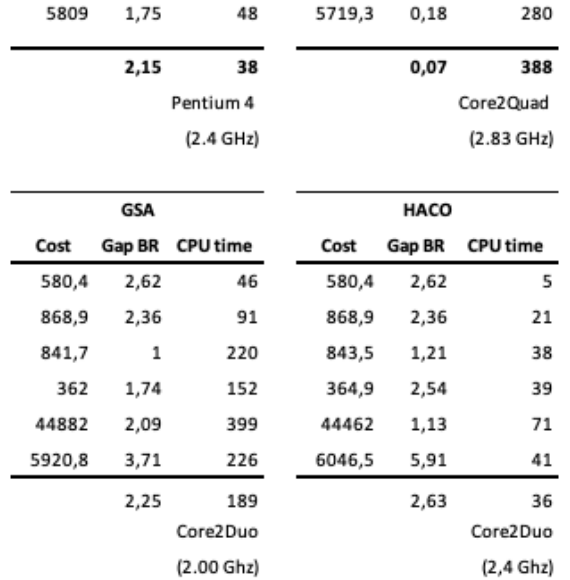

Source: Owner 
Table 5

\begin{tabular}{ll}
\hline & \\
Instance & BR \\
\hline 111112 & $\mathbf{1 4 7 3 , 4}$ \\
111122 & $\mathbf{1 4 4 9 , 2}$ \\
132222 & $\mathbf{9 3 1 , 4 4}$ \\
123222 & $\mathbf{1 3 9 0 , 7}$ \\
\hline Average & \\
CPU &
\end{tabular}

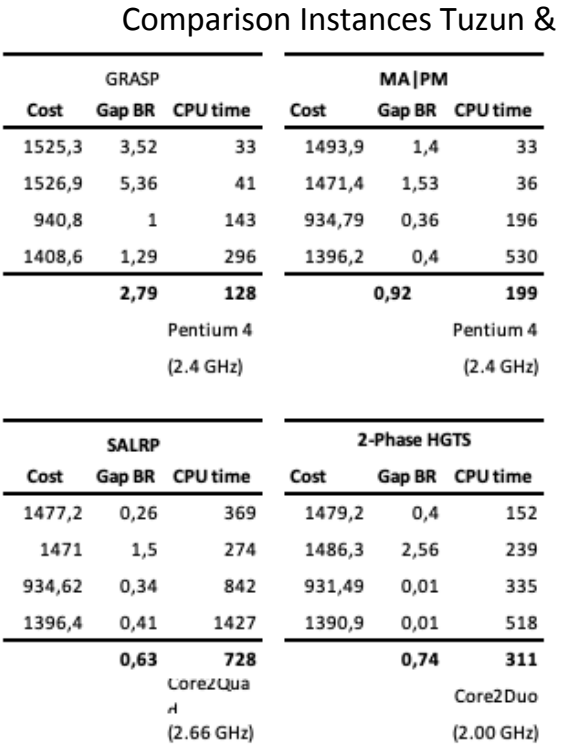

\begin{tabular}{lrr} 
Burke (1999) \\
\hline \multicolumn{3}{c}{ LRGTS } \\
Cost & Gap BR & CPU time \\
\hline 1490,8 & 1,19 & 3 \\
1471,8 & 1,56 & 8 \\
936,93 & 0,59 & 14 \\
1401,2 & 0,75 & 43 \\
\hline & $\mathbf{1 , 0 2}$ & $\mathbf{1 7}$ \\
& & Pentium 4
\end{tabular}

\begin{tabular}{lrr}
\hline \multicolumn{3}{c}{ GRASP + ELS } \\
Cost & Gap BR & CPU time \\
\hline $\mathbf{1 4 7 3 , 4}$ & 0 & 233 \\
$\mathbf{1 4 4 9 , 2}$ & 0 & 9 \\
945,81 & 1,54 & 224 \\
1453,8 & 4,54 & 2202 \\
\hline & $\mathbf{1 , 5 2}$ & $\mathbf{6 6 7}$ \\
& & Core2Quad
\end{tabular}

\begin{tabular}{lrr} 
& & \\
\hline \multicolumn{3}{c}{ GSA } \\
Cost & Gap BR & CPU time \\
\hline 1490,8 & 1,19 & 151 \\
1486,3 & 2,56 & 244 \\
$\mathbf{9 3 1 , 4 4}$ & 0 & 320 \\
1390,7 & 0 & 489 \\
\hline \multicolumn{4}{c}{$\mathbf{0 , 9 4}$} & $\mathbf{3 0 1}$ \\
& \multicolumn{3}{c}{ Core2Duo } \\
& & $(2.00 \mathrm{GHz})$
\end{tabular}

\begin{tabular}{lrr} 
& & \\
& & $(2.83 \mathrm{GHz})$ \\
\multicolumn{3}{c}{ HACO } \\
Cost & Gap BR & CPU time \\
\hline 1476,3 & 0,2 & 29 \\
1486,6 & 2,58 & 75 \\
937,25 & 0,62 & 235 \\
1451,3 & 4,35 & 345 \\
\hline & 1,94 & 171 \\
& & Core2Duo \\
& & (2,4 Ghz)
\end{tabular}

Source: Owner

We have applied the following notation for the tables:
Instance: $\quad$ Name of the instance;
Cost: $\quad$ Cost of the solution obtained by each method (in only one run or the best run);
BR: $\quad$ Cost of the best result found by the considered algorithm;
Gap BR: $\quad$ Percentage variation of the cost found by each algorithm concerning the BR value;
CPU time: Execution time in seconds in the used CPU for each algorithm;
Average: $\quad$ Average of the column values;
CPU: $\quad$ CPU used by each algorithm.

Therefore, it can be noticed that in the Gap BR column, the suggested algorithm obtains good solutions compared to the algorithms of the literature. It is displayed that such an algorithm gives better results than other algorithms. On the other hand, it might be considered that the algorithm gives the solution in a reduced computational time (CPU time).

Mainly, the average difference of the objective functions' values, compared to the cost of the best result, is analyzed (Average column). In this way, the average difference is obtained, identifying a reduced average difference concerning the algorithms' best result. Consequently, feasibility in the algorithm is shown.

Although the best results of the literature were not achieved, the ACO algorithms applied to the LRP prove to be efficient in quality versus computational time, with only an average gap of $2.258 \%$.

\section{Conclusions}

We proposed a metaheuristic algorithm for the CLRP based on Ant Colony Optimization. When the ACO algorithm gave different feasible solutions, it searched for new alternatives for the LRP problem. Therefore, since the algorithm is stochastic, it is concluded that it allowed increasing the diversification of solutions and intensifying the best solutions. 
The future researches that might be presented to solve the Location Routing Problem with ACO following the same investigation line are:

1. Develop the use of multiple ant colonies.

2. Implement new strategies to improve the algorithm, monitoring the pheromone concentration in the different global and local updating strategies.

\section{References}

Asmar, D., Elshamli, A., \& Areibi, S. (2005). A comparative assessment of ACO algorithms within a TSP environment. Dynamics of Continous Discrete and Impulsive Systems-Series B-Applications \& Algorithms, 1, 462-467.

Baldacci, R., Mingozzi, A., \& Wolfler Calvo, R. (2011). An exact method for the capacitated location-routing problem. Operations research, 59(5), 1284-1296.

Barceló, J., \& Casanovas, J. (1984). A heuristic Lagrangean algorithm for the capacitated plant location problem. European Journal of Operational Research, 15(2), 212-226.

Barreto, S. D. S. (2004). Análise e Modelização de Problemas de localização-distribuição (Doctoral dissertation, Universidade de Aveiro).

Beardwood, J., Halton, J. H., \& Hammersley, J. M. (1959). The shortest path through many points. In Mathematical Proceedings of the Cambridge Philosophical Society. Vol. 55, No. 4, pp. 299-327. Cambridge University Press.

Belenguer, J. M., Benavent, E., Prins, C., Prodhon, C., \& Calvo, R. W. (2011). A branch-and-cut method for the capacitated location-routing problem. Computers \& Operations Research, 38(6), 931-941.

Caballero, R., González, M., Guerrero, F. M., Molina, J., \& Paralera, C. (2007). Solving a multiobjective location routing problem with a metaheuristic based on tabu search. Application to a real case in Andalusia. European Journal of Operational Research, 177(3), 1751-1763.

Clarke, G., \& Wright, J. W. (1964). Scheduling of vehicles from a central depot to a number of delivery points. Operations research, 12(4), 568-581.

Colorni, A., Dorigo, M., \& Maniezzo, V. (1992). An Investigation of some Properties of an" Ant Algorithm". In Ppsn, Vol. 92, No. 1992.

Contardo, Claudio., Cordeau, J. F., \& Gendron, Bernard (2010). A branch-and-cut algorithm for the capacitated location-routing problem. In Conference CAOR (Vol. 10).

Dantzig, G. B., \& Ramser, J. H. (1959). The truck dispatching problem. Management science, 6(1), 80-91.

Dorigo, M. (1992). Optimization, learning and natural algorithms. Ph. D. Thesis, Politecnico di Milano.

Dorigo, M., Maniezzo, V., \& Colorni, A. (1996). Ant system: optimization by a colony of cooperating agents. IEEE Transactions on Systems, Man, and Cybernetics, Part B (Cybernetics), 26(1), 29-41.

Dorigo, M., \& Gambardella, L. M. (1997). Ant colony system: a cooperative learning approach to the traveling salesman problem. IEEE Transactions on evolutionary computation, 1(1), 53-66. 
Dorigo M., Stützle T. (2019) Ant Colony Optimization: Overview and Recent Advances. In: Gendreau M., Potvin JY. (eds) Handbook of Metaheuristics. International Series in Operations Research \& Management Science, vol 272. Springer, Cham. https://doi.org/10.1007/978-3-319-91086-4_10.

Duhamel, C., Lacomme, P., Prins, C., \& Prodhon, C. (2010). A GRASP× ELS approach for the capacitated locationrouting problem. Computers \& Operations Research, 37(11), 1912-1923.

Escobar, J. W., \& Linfati, R. (2012). Un algoritmo metaheurístico basado en recocido simulado con espacio de búsqueda granular para el problema de localización y ruteo con restricciones de capacidad. Revista Ingenierías Universidad de Medellín, 11(21), 139-150. Available in https://revistas.udem.edu.co/index.php/ingenierias/article/view/604/545

Escobar, J. W., Linfati, R., \& Toth, P. (2013). A two-phase hybrid heuristic algorithm for the capacitated locationrouting problem. Computers \& Operations Research, 40(1), 70-79.

Escobar, J. W., Linfati, R., \& Adarme-Jaimes, W. (2015). A hybrid metaheuristic algorithm for the capacitated location routing problem. Dyna, 82(189), 243-251.

Farkavcova, V. G., Rieckhof, R., \& Guenther, E. (2018). Expanding knowledge on environmental impacts of transport processes for more sustainable supply chain decisions: A case study using life cycle assessment. Transportation Research Part D: Transport and Environment, 61, 68-83.

García, L. A. M. (2016). GESTION LOGISTICA INTEGRAL: las mejores practicas en la cadena de abastecimiento . Ecoe Ediciones. Retrieved from: https://www.ecoeediciones.com/wp-content/uploads/2016/12/Gestionlogistica-integral-2da-Edici\%C3\%B3n.pdf

Garey, M. R., \& Johnson, D. S. (1979). Computers and Intractability: A Guide to the Theory of NP-Completeness. WH Freeman \& Co. New York, NY, USA.

Harks, T., König, F. G., \& Matuschke, J. (2013). Approximation algorithms for capacitated location routing. Transportation Science, 47(1), 3-22.

Helsgaun, K. (2000). An effective implementation of the Lin-Kernighan traveling salesman heuristic. European Journal of Operational Research, 126(1), 106-130.

i Cos, J. P., \& De Navascués, R. (1998). Manual de logística integral. Ediciones Díaz de Santos. Retrieved from: http://www.diazdesantos.com.co/libros/pau-i-cos-jordi-manual-de-logistica-integral-L03003450303.html

Laporte, G., Louveaux, F., \& Mercure, H. (1989). Models and exact solutions for a class of stochastic locationrouting problems. European Journal of Operational Research, 39(1), 71-78.

Linfati, R., Escobar, J. W., \& Gatica, G. (2014). A metaheuristic algorithm for the location routing problem with heterogeneous fleet. Ingeniería y Ciencia, 10(19), 55-76.

Luna López, L. C. (2015). Localización de paradas y diseño óptimo de rutas para transporte de personal (Doctoral dissertation, Universidad Autónoma de Nuevo León). Retrieved from: http://eprints.uanl.mx/9541/1/1080214944.pdf

Mehrjerdi, Y. Z., \& Nadizadeh, A. (2013). Using greedy clustering method to solve capacitated location-routing problem with fuzzy demands. European Journal of Operational Research, 229(1), 75-84. 
Negrotto, D. (2015). Algoritmos para el problema de localización y ruteo de vehículos con capacidades y premios (Doctoral dissertation, Universidad de Buenos Aires. Facultad de Ciencias Exactas y Naturales). Retrieved from: https://bibliotecadigital.exactas.uba.ar/download/tesis/tesis_n5818_Negrotto.pdf

Prins, C., Prodhon, C., \& Calvo, R. W. (2006a). A memetic algorithm with population management (MA| PM) for the capacitated location-routing problem. In European Conference on Evolutionary Computation in Combinatorial Optimization (pp. 183-194). Springer, Berlin, Heidelberg.

Prins, C., Prodhon, C., \& Calvo, R. W. (2006b). Solving the capacitated location-routing problem by a GRASP complemented by a learning process and a path relinking. 4OR, 4(3), 221-238.

Prins, C., Prodhon, C., Ruiz, A., Soriano, P., \& Wolfler Calvo, R. (2007). Solving the capacitated location-routing problem by a cooperative Lagrangean relaxation-granular tabu search heuristic. Transportation Science, 41(4), 470-483.

Stützle, T., \& Ruiz, R. (2018). Iterated Local Search: A Concise Review. IRIDIA, Institut de Recherches Interdisciplinaires et de D'eveloppements en Intelligence Artificielle, Universite Libre de Bruxelles, Technical Report. Belgium

Tokgoz, E., \& Trafalis, T. B. (2014). Manifold Location Routing Problem with Applications in Network Theory. In International Conference on Network Analysis, pp. 89-114. Springer, Cham.

Toro, E. M., Franco, J. F., Echeverri, M. G., \& Guimarães, F. G. (2017). A multi-objective model for the green capacitated location-routing problem considering environmental impact. Computers \& Industrial Engineering, 110, 114-125.

Toth, P., \& Vigo, D. (2002). Models, relaxations and exact approaches for the capacitated vehicle routing problem. Discrete Applied Mathematics, 123(1-3), 487-512.

Tuzun, D., \& Burke, L. I. (1999). A two-phase tabu search approach to the location routing problem. European journal of operational research, 116(1), 87-99.

Vasquez Delgado (2012), Implementación de un algoritmo basado en la Búsqueda Tabú para la resolución de un problema de ruteo de vehículos con ventana temporal de acceso. Capítulo 4 resolución del problema de ruteo de vehículos VRP, Francisco de asís. Escuela técnica superior de ingenieros, Universidad de Sevilla. pp. 27-39.

Vincent, F. Y., Lin, S. W., Lee, W., \& Ting, C. J. (2010). A simulated annealing heuristic for the capacitated location routing problem. Computers \& Industrial Engineering, 58(2), 288-299.

Watson-Gandy, C. D. T., \& Dohrn, P. J. (1973). Depot location with van salesmen-a practical approach. Omega, 1(3), 321-329.

Webb, M. H. J. (1968). Cost functions in the location of depots for multiple-delivery journeys. Journal of the Operational Research Society, 19(3), 311-320.

Wu, T. H., Low, C., \& Bai, J. W. (2002). Heuristic solutions to multi-depot location-routing problems. Computers \& Operations Research, 29(10), 1393-1415.

Esta obra está bajo una Licencia Creative Commons Attribución-NoCommercial 4.0 International

(cc) $\overline{\text { BY-NC }}$ 